\title{
Artelogie
}

Recherche sur les arts, le patrimoine et la littérature de l'Amérique latine

5 | 2013

Femmes créatrices en Amérique latine : le défi de synthétiser sans singulariser

\section{Clara Porset, diseño e identidad}

Ana Elena Mallet

\section{(2) OpenEdition}

Journals

Edición electrónica

URL: https://journals.openedition.org/artelogie/5487

DOI: 10.4000/artelogie.5487

ISSN: 2115-6395

Editor

Association ESCAL

Referencia electrónica

Ana Elena Mallet, «Clara Porset, diseño e identidad», Artelogie [En línea], 5 | 2013, Publicado el 16 octubre 2013, consultado el 20 diciembre 2021. URL: http://journals.openedition.org/artelogie/5487 DOI: https://doi.org/10.4000/artelogie.5487

Este documento fue generado automáticamente el 20 diciembre 2021.

Association ESCAL 


\title{
Clara Porset, diseño e identidad
}

\author{
Ana Elena Mallet
}

\section{Clara Porset, diseño e identidad}

1 Clara Porset Dumas es considerada una de las más destacadas diseñadoras mexicanas del siglo XX, a pesar de haber nacido en Matanzas, Cuba el 25 de mayo de 1895, vivió y trabajó en México la mayor parte de su vida y su legado es hoy parte fundamental de la historia del diseño nacional.

Descendiente de una familia acomodada, Porset siempre tuvo interés en el diseño y las manualidades, y gracias a la posición familiar tuvo acceso a una educación internacional que influyó enormemente en sus diseño.

Entre 1914 y 1918 realizó sus estudios secundarios en Manhatanville Academy en Nueva York. A su regresó a Cuba se encontró con que su familia enfrentaba una frágil situación económica; con mucho ahínco, comenzó a realizar diversos trabajos que le permitieron costearse algunos cursos de estudios técnicos de arquitectura y diseño. En 1925 volvió a Nueva York para cursar el bachillerato en Artes en la Escuela de Bellas Artes de la Universidad de Columbia, esta estancia le abrió los ojos y terminó por convencerla que el diseño sería su vida. Entre 1928 y 1931 viajó a París para estudiar arquitectura y diseño de muebles al taller del arquitecto Henri Rapin y su pasión fue tal que su tiempo libre lo dedicó a asistir como oyente a cursos sobre historia de la arquitectura, historia del arte y teorías de la arquitectura en la Escuela de Bellas Artes. Tomó también un curso sobre estética en la Sorbona y otros sobre arte en el Museo de Louvre. Aprovechó los veranos para recorrer diversos puntos de Europa como Francia y a España, Italia, Suiza, Bélgica, Holanda e Inglaterra y empaparse de la arquitectura y el diseño de aquellos países.

4 Para 1932 volvió a La Habana dando inicio a su trabajo profesional como diseñadora de muebles para residencias, clubes, hospitales y escuelas. A través de su obra y diversas conferencias y artículos, introdujo en Cuba el nuevo concepto de arquitectura y mueble. Colaboró en la revista Social buscando divulgar las nuevas vertientes de la profesión. Su compromiso y la contundencia de su propuesta se vio reflejado en una 
ponencia que leyó el 22 de mayo de 1931 en el Auditórium de La Habana titulada: "La decoración interior contemporánea su adaptación al trópico" en la que se declaraba en contra del término "decoración interior" ya que no iba acorde al espíritu de la época y proponía cambiarlo por "diseño de interiores" pues en la actividad no hay nada de decorativo sino una "cuestión de perfección de formas y de relación de masas" 1

Determinada y aguerrida, Porset fue poco a poco ganándose un lugar como la diseñadora más destacada del momento en la isla, sin embargo, el éxito local le satisfizo poco y buscó nuevos horizontes donde profesionalizarse.

En el verano de 1934 llegó a Black Mountain College donde Josef y Anni Albers, -artistas y diseñadores emigrados de la escuela de la Bauhuas- impartían una serie de cursos que sin duda tuvieron una influencia determinante en Porset. Los Albers además, se convirtieron en amigos cercanos de la diseñadora, invitado por ella Josef Albers llegó por primera vez a La Habana (1934) y posteriormente a México donde el matrimonio pasaría largas temporadas.

7 Consternada por la terrible situación política, económica y social que vivía su país en 1934 Porset se unió al Partido Comunista y en 1935 formó parte del contingente de la huelga general de Cuba, lo que le ocasionaría perder su trabajo en la Escuela Técnica para Mujeres, y que sus clientes le dieran las espalda negándose a darle más trabajo. En 1936 una oferta para sustituir al poeta Carlos Pellicer en la cátedra de Historia del Arte en la escuela de verano de la Universidad Autónoma de México cambiaría el rumbo de su vida.

8 Al llegar a México, la diseñadora se da cuenta que en el país existe un clima propicio para el desarrollo artístico y la actividad política y se involucra lo mismo con artistas y arquitectos de la época que con grupos de exiliados cubanos, en este grupo esta el pintor Xavier Guerrero con quien se identificó inmediatamente ya que compartían el compromiso político. En 1938 se casó con Xavier Guerrero estableciéndose definitivamente en México donde la pareja comenzaría una interesante colaboración profesional. El pintor, coleccionista y amante de las artes populares introdujo a la diseñadora en las artes populares y el mobiliario tradicional mexicano, que sería la fuente de inspiración de Porset el resto de su vida.

En 1941 el matrimonio participó en el concurso Organic Design for Home Furnishing (Diseño Orgánico para Mobiliario Habitacional) convocado por el Museo de Arte Moderno (MoMA) de Nueva York, que por primera vez, incluía a diseñadores latinoamericanos en su convocatoria $\mathrm{El}$ concurso era patrocinado por doce grandes almacenes en las principales ciudades de Estados Unidos de América, que se comprometían junto a varios fabricantes, a producir y comercializar los muebles premiados. El director del departamento de diseño industrial de la institución, Eliot Noyes fue quien impulsó este concurso entre los diseñadores y empresas productoras más conocidos y convocó además, a los diseñadores de muebles de las 21 naciones de América Latina. La intención desde MoMA era impulsar la producción y el consumo local en un periodo de guerra y estimular el mercado estadounidense. Hacerlo desde la institución cultural resultó una estrategia tan exitosa que se replicó en varias ocasiones.

10 La respuesta de aquel primer concurso fue muy nutrida y estimulante, pues tan sólo de Latinoamérica llegaron trabajos de 17 países. En la categoría norteamericana, los participantes más destacados fueron los jóvenes egresados de la Academia Cranbrook, Eero Saarinen y Charles Eames que en muy poco tiempo destacarían a nivel 
internacional gracias a los muebles que desarrollaron para este certamen. Los asientos que se estructuraban a partir de chapas de madera moldeadas, eran tan novedosos que no hubo industrial que pudiera fabricarlos en aquel momento, y los gabinetes para guardado, eran realmente avanzados por su estandarización, su capacidad de intercambiarse y su fácil adaptación.

11 Para Latinoamérica se otorgaron cuatro premios para los mejores trabajos: Uno para Julio Villalobos de Buenos Aires, otro para Bernardo Rudofski (aunque de origen austríaco en esos años residía y trabajaba en Sao Paulo y representó a Brasil), y dos para México: los diseñadores Michael van Beuren y Klaus Grabe, ex alumnos de la Bauhaus, acompañados por su socio Morley Webb, presentaron un excelente asiento para descanso tipo chaise longue fabricado por Domus, uno de los talleres de producción más creativos en el país dirigido por Van Beuren ${ }^{2}$. Porset y Guerrero, presentaron un conjunto de bajo costo al que llamaron mobiliario rural, diseñado para campesinos mexicanos.

12 Si bien se inscribieron en dueto, Porset fue la única mujer inscrita en ese concurso. De alguna manera la situación de aquel momento para las mujeres en el diseño se refleja en la problemática que se dio en la Bauhaus.

13 En un principio la destacada escuela estaba reacia a tomar mujeres como alumnas sin embargo al abrir las puertas al otro género un tercio del alumnado resultaron mujeres. Después de todo, la escuela estaba situada en la República de Weimar donde constitucionalmente, las mujeres podían estudiar donde eligieran. La imagen masculina que proyectaba la escuela así como el hecho de que el 95\% del profesorado eran hombres, vaticinaba una situación difícil para las alumnas. En su primer discurso como director de la Bauhaus en abril de 1919 de bienvenida, Walter Gropius habló a los estudiantes de la igualdad entre géneros "No habrá distinción entre el sexo bello y el fuerte. Derechos absolutamente iguales pero también responsabilidades equitativas. No habrá consideraciones para las damas; en el trabajo todos serán artesanos. Me opondré rotundamente a que se limiten a pintar lindos cuadritos de Salón para pasar el tiempo"3. A pesar de la dureza y exigencias de la Bauhaus y el afán por convertir a las mujeres en artesanos profesionales, lo cierto es que la situación social real en Alemania era bastante compleja ya que las mujeres artesanos y diseñadoras no eran aceptadas y era realmente difícil conseguir un trabajo. Sin embargo, el tesón de las mujeres que estudiaron en la Bauhaus como Gunta Stölzl, Marianne Brandt y Alma Buscher, aunado al patronazgo que algunos de los maestros les brindaron y la construcción de una red de contactos profesionales cambiaron poco a poco la situación laboral de las mujeres de la Bauhaus.

14 En 1946 Porset regresó a Nueva York para establecer contacto con la firma de muebles Artek-Pascoe que ya entonces, representaba a importantes figuras del diseño. La casa mueblera -que en aquellos años de guerra producía materiales para la defensa estadounidense y una vez terminado el conflicto se fue a la quiebra- le solicitó un conjunto de muebles y le ofreció una exposición en sus instalaciones ubicadas en el número 16 al este de la calle 49, (16 East Forty-ninth Street). Al regresar a México y con el pedido asegurado, Porset buscó a Michael van Beuren, propietario y diseñador de la marca Domus quien se encargó de producir sus diseños con el fin de alcanzar los estándares de calidad que solicitaba la empresa estadounidense. En febrero de 1947, tal y como lo registró el periódico New York Times, ${ }^{4}$ se inauguró en la tienda de ArtekPascoe, una exposición que presentaba el conjunto de muebles diseñado por Clara 
Porset. Si bien la sociedad estadounidense tenía ya una cierta curiosidad por el país vecino, lo cierto es que en estos años, empezaron a descubrir sus riquezas y, con Europa en guerra, México se convirtió en un destino casi obligado. Las cosas que sucedían al sur de la frontera de pronto pasaron a ser de mayor interés, así lo relata la reportera, Mary Roche, en la breve nota que para el New York Times escribió sobre el trabajo de Porset en Nueva York: "Mientras que muchos viajeros recuerdan México como una mezcla del viejo español y el indígena nativo, visitantes recientes han traído reportes de una nueva arquitectura y un nuevo tipo de decoración que resultan ser modernos y poco pretencioso". ${ }^{5}$ Los muebles de Clara Porset para Artek-Pascoe, venían a confirmar estas afirmaciones pues se alejaban de lo que tradicionalmente, se había considerado como "mexicano". Con pequeños toques artesanales, el mobiliario de Porset resultó una bocanada de aire fresco para el entorno. El conjunto consistía en cinco muebles básicos realizados en cedro, propuestos para un pequeño departamento de una sola recámara. Una cómoda para guardar diversas cosas que bien podía entregarse con repisas interiores fijas para colocar platos o utensilios de cocina, o repisas corredizas para guardar ropa y blancos. La cama de tamaño individual tenía la parte de los pies y la cabecera del mismo tamaño por lo que podía colocarse también, al lado de una pared y usarse como sillón o cama de día. Una mesa de comedor de cedro macizo con un pedestal del que se desprendían cuatro brazos que sostenían la base y otros ocho brazos que se dirigían hacia el piso. Una pequeña mesa multiusos -que lo mismo se proponía como escritorio que como mesa para servir o tocador- que asemejaba a una repisa de vidrio, sostenida en un lado por un par de patas de madera delgada y en el otro, por un pedestal de tres cajones. La pieza que más llamó la atención y que en el mismo artículo la autora describe como "la que realmente muestra su herencia mexicana", es el clásico butaque por el que fue muy conocida Clara Porset. Pero a diferencia de sus tradicionales modelos que tenían el asiento de ixtle o de baqueta, en esta ocasión Porset se decidió por forrarlos de tela con diferentes patrones; así, se ofrecían cuatro tipos de estampados con brillantes colores. La exposición y la venta de los muebles fue un éxito.

El segundo concurso en el que Porset participó en los Estados Unidos fue Prize Design for Modern Furniture en 1948, también organizado por el MoMA en Nueva York. En esta ocasión, la diseñadora presentó una silla con estructura de fierro y asiento tejido en mimbre, que a pesar de no haber sido premiada, apareció en el catálogo.

La trienal de Milán en 1957 fue la culminación de los reconocimientos recibidos en vida. Porset inscribió al certamen una serie de muebles para exteriores que había desarrollado para el hotel Pierre Marqués en Acapulco y que habían sido producidos por Industrias Ruiz Galindo (Irgsa). Madera de otate curvada y tejidos artesanales mexicanos conformaban la estructura de este mobiliario que fue concebido en un pulcro estilo orgánico, muy en boga en aquellos días. La XI edición de este importante evento, culminó con Clara Porset obteniendo la Medalla de Plata por la originalidad y el buen diseño de este conjunto de muebles.

\section{El Butaque}

De la mano de Xavier Guerrero, Clara Porset visitó una gran cantidad de poblaciones en territorio mexicano. Supo acercarse al trabajo de los artesanos y logró apreciar los más pequeños detalles y las piezas más complejas. Observadora y tenaz, encontró en el 
butaque -asiento tradicional que en cada región tiene una versión distinta- una fuente de inspiración y constante experimentación.

Si bien otros diseñadores mexicanos como William Spratling y Héctor Aguilar en Taxco habían hecho ya algunas reinterpretaciones de los butaques fue Clara Porset quien los analizó formalmente a conciencia, realizando además, un profuso estudio ergonómico. Luego de varios años de experimentación, la diseñadora logró un interesante rescate cultural de este mobiliario.

Su análisis partió de entender cómo este asiento se enfocaba en el aprovechamiento de la madera, logrando la curvatura de patas, asiento y respaldo con tablas de pequeña sección que generaban poco desperdicio y se unían mediante un ensamble muy seguro gracias a la gran superficie de contacto entre las piezas.

Porset se percató de que la curva continua que integra el asiento y el respaldo es un elemento central que si esta mal trazado, impide la comodidad y la facilidad de uso. Experimentó con variantes en las dimensiones de la estructura y sustituyó el material usado en el asiento probando una gran variedad de tejidos de distintas fibras. A lo largo de varios años, se concentró en un proceso de cambio que implicó un análisis ergonómico de la estructura del butaque para modificarla, logrando diversas proporciones, acabados distintos y un interesante proceso formal.

21 Si bien los butaques son las piezas más representativas de esta diseñadora su trabajo no se limitó a ellos, experimentó con materiales como maderas locales y diversas fibras naturales, se inspiró en formas tradicionales pero también en las esculturas prehispánicas y en piezas de arte popular. Consiguió desarrollar un lenguaje propio que fue muy bien recibido en aquellos años. El arquitecto Luis Barragán, confió a esta diseñadora sus mejores obras para que desarrollará el mobiliario: Casa Gálvez (1954-55) y la propia casa-estudio del arquitecto en Tacubaya (1947) son un par de ejemplos donde no faltaron butaques, biombos y muebles para guardado.

\section{Un mundo de hombres: Clara Porset y los arquitectos modernos mexicanos}

En los últimos años de la década de los 1940 y principios de los 1950, Clara Porset se destacó por realizar colaboraciones con importantes arquitectos. No había entonces otras mujeres en el medio y Porset se desarrollaba en un entorno completamente masculino. Todos los arquitectos de entonces eran hombres y las mujeres tenían poca cabida en el mundo del diseño y la construcción. Dos referentes femeninos del momento fueron: María Luisa Dehesa (Jalapa, Veracruz, 1912) la primera mujer en titularse de la carrea de arquitectura en la Real Academia de San Carlos en 1939 que ejerció poco, pues de sus diseños sólo destaca en los registros su propia casa en la colonia del Valle de la ciudad de México. Sin embargo la tesis con la que se tituló "Cuartel de Artillería Tipo", buscaba transgredir su condición de mujer ocupándose de un tema tradicionalmente masculino.

Ruth Rivera Marín (ciudad de México, 1927-1969) fue otra destacada arquitecta, la primera mujer en ingresar a la Escuela Superior de Ingeniería y Arquitectura del Instituto Politécnico Nacional. Rivera Marín se dedicó a la enseñanza y desde 1959 hasta su muerte fue la titular del departamento de Arquitectura del Instituto Nacional de Bellas Artes (INBA). 
Así Porset se vio obligada a trabajar en un mundo de hombres donde su férreo carácter y su determinación le ayudaron a mantenerse a flote. ${ }^{6}$

El desarrollo de proyectos integrales implicaban un importante y dedicado trabajo conjunto y las colaboraciones con arquitectos fueron cada vez más recurrentes.

Pareciera importante señalar que los arquitectos con los que trabajó Porset eran la camada que estaba delineando el nuevo México, el que prometía ser Moderno que, a través de las artes plásticas primero y la arquitectura después, había logrado atraer la mirada del mundo.

7 Entonces, existían también otros movimientos artísticos que influían lo mismo en la plástica que en arquitectura y, por ende en el diseño y la decoración. Específicamente hay que referirse al Neobarroco -estilo que proliferó en las construcciones de las colonias Polanco y las Lomas de Chapultepec en la capital de la República- que desató debates entre los arquitectos modernos: un bando buscaba librarse de la carga colonial pero sin virar demasiado a las tendencias europeas del momento mientras que otro grupo, más tradicional, buscaban anclar un fundamento formal en el pasado español. La arquitectura moderna representaba la nueva identidad nacional; la Neobarroca el pasado colonial que era necesario dejar atrás con el fin de evolucionar. A través de estas discusiones se buscaba lograr la definición de nueva identidad mexicana y, la estética, sobre todo la moderna, fue fundamental para conseguirlo. Tal y como había sucedido en las artes plásticas; la arquitectura, la decoración y el diseño comenzaron a tener connotaciones políticas: contratar a Mario Pani, a Juan O'Gorman o a Juan Sordo Madaleno -más allá de los resultados estéticos o estilísticos-, no significaba lo mismo que pedirle un proyecto al arquitecto Luis Martínez Negrete o al Ingeniero Carlos B. Palencia. ${ }^{7}$

Las posturas políticas de izquierda, además de sus tendencias estéticas inclinadas hacia la Bauhaus, llevaron a Clara Porset a identificarse más con los arquitectos modernos que buscaban, a través de sus construcciones, darle a la ciudad de México y después al país, una identidad actual que pudiera insertarse en el mundo moderno. Las propuestas de diseño de Porset, ancladas en la tradición popular y con la imagen de un espíritu nacional, dialogaban a la perfección con la nueva arquitectura mexicana. Buscando concebir un mobiliario que a la vez que mexicano fuera también moderno, Porset logró la evolución del mobiliario popular y que éste, adquiriera nuevas connotaciones simbólicas. Mientras que los usuarios del estilo colonial californiano o Neobarroco eran españoles, libaneses y judíos recién llegados al país ${ }^{8}$, los clientes de Clara Porset aquellos que decidían trabajar con los arquitectos modernos- representaban una nueva clase profesional y empresarial, joven y entusiasta, que era la que -se suponía- iba a guiar a México hacia el progreso. La diseñadora realizó trabajos para las casas de Bernardo Quintana y Luis García Barbachano, socios de ICA (Ingenieros Civiles Asociados) una nueva empresa de construcción, netamente mexicana. Realizó los muebles e interiores de la fábrica Chrysler construida por los arquitectos Guillermo Rosell y Lorenzo Carrasco y propiedad de Gastón Azcárraga Jr., para quien posteriormente, realizó los muebles de su casa particular. Pero el trabajo de Porset no sólo permeó las clases empresariales sino que también creo propuestas para la clase intelectual mexicana de la que ella misma era parte. Diseñó muebles para las residencias de la fotógrafa Lola Álvarez Bravo, el arqueólogo Alberto Rus, el museógrafo Fernando Gamboa y el pintor José Clemente Orozco entre varios otros. 


\section{Clara Porset y el contexto del diseño de interiores en México} Mario Pani- y que había estudiado en La École des Beaux Arts. A su regreso a México en 1935 tomó su primer proyecto que fue la decoración y el diseño de mobiliario para la casa familiar que se encontraba en la calle de Lieja. Esta obra marcaría mucho de lo que Pani haría después, ya que hubo que encontrar soluciones para hacer convivir las antigüedades y piezas de arte que a lo largo de su vida habían adquirido sus padres, con nuevos muebles y accesorios de reciente producción, diseñados por él. El primer gran proyecto del arquitecto Mario Pani a su regreso al país, fue un encargo de su tío Alberto J. Pani, la construcción del Hotel Reforma (1936), que se convirtió en un emblema de la modernidad mexicana. Mario Pani, tendió la mano a su hermano y le dieron carta blanca para realizar el mobiliario y el diseño interior del lobby y algunos salones. La decoración del gran hotel resultó en una combinación de estilos europeos antiguos y muebles hechos a medida con toques modernos. La red de relaciones sociales que tenía la familia, así como su carácter afable, lograron que pronto encontrara trabajo fijo en una empresa de decoración que se llamaba De la Peña, Lascuráin y Compañía, que dirigía el anticuario Antonio de la Peña quien, como Pani, optaba por decoraciones que mezclaran la tradición con lo nuevo. Dicha casa de decoración aprovecho el nombre de Pani -a quien en estos primeros años presentaban como Arturo Pani Jr.-, que figuraba en los anuncios impresos de las revistas de alta circulación como el decorador principal de dicha casa. Pani era arriesgado y sabía combinar todo tipo de materiales, aunque su gusto era más bien europeo; se adaptaba a cualquier situación y sobre todo a las necesidades del cliente.

Luego de 1939 con el exilio español llegaron al país un buen número de arquitectos y pintores que al no encontrar trabajo en sus respectivas áreas-tal es el caso de Eduardo Robles Piquer que llegó a México con un grupo de republicanos españoles que venían huyendo de los estragos de la Guerra Civil y la persecución franquista. Había nacido en Madrid y estudiado en la Escuela Superior de Arquitectura, donde recibió su diploma en 1935. Desde 1932, venía publicando caricaturas en diversos diarios y revistas españoles como Sol, As, Crónica, Estampa y Gutiérrez, en los que firmaba como Robles. Participó activamente en la Guerra Civil al mando de los equipos de bombardeo, organizados por el colegio de arquitectos. En 1939 fue llevado al campo de concentración de Saint Cyprien al sur de Francia. Al llegar a la ciudad de México trabajó en la empresa Constructores Hispano Mexicanos. En 1941 fundó, en sociedad con Cayetano de la Jara, la casa de decoración y materiales para artistas Ras-Martín, cuya primera sede se encontraba en la Calle de Palma 12 departamento 18, en el centro de la ciudad de México. Comenzó a publicar caricatura política en Dictamen de Veracruz, Estampa., 
Novedades, Mujeres y Deportes y en el Semanario Don Timorato. Durante varios años combinó su práctica como caricaturista con su labor en la decoración, el interiorismo y el paisajismo, y en 1952, en mancuerna con Enrique F. Gual, crítico de arte y también exiliado español, fundó la revista Decoración que se publicaría hasta 1957, año en el que Robles Piquer partió a vivir a Venezuela.

Durante el tiempo que estuvo a cargo de Ras-Martín, esta casa se convirtió en una de las más productivas y creativas de México. Sus talentos para la decoración y las relaciones públicas hicieron que, poco a poco, Ras-Martín se convirtiera en una de las casas favoritas de la nueva clase alta mexicana. Robles Piquer tuvo la visión de emplear a muchos de los artistas españoles-Blandino García Ascot, Ramón Peinador-que se encontraban en México, consiguiendo que el exilio español en el país fuera el iniciador de un movimiento de decoración y diseño que florecería con la bonanza del México de los años cincuenta. Los españoles, además de destreza y preparación, tenían la información necesaria para desarrollar y adaptar a este país las últimas tendencias del viejo continente y los estilos europeizantes que tanto atraían a la sociedad mexicana. Además de casa de interiorismo, Ras-Martín tenía un espacio para exponer obra de distintos artistas. Hacia finales de la década de 1940, el modelo Ras-Martín se replicó, y nacieron decenas de casas de decoración, muchas de ellas dirigidas por artistas españoles que habían trabajado bajo la tutela de Robles. Tales fueron los casos de Blandino García Ascot, que abrió Ascot, e Ignacio Canadell director artístico de ClareDecor. Ras-Martín se aventuró a realizar una gran cantidad de diseño interior para casas privadas, oficinas, hoteles y restaurantes, pero también incursionaron con gran tino en la decoración de interior de tiendas y locales comerciales, lo mismo que en el diseño de aparadores y displays, así como exposiciones comerciales

\section{El Centro Urbano Presidente Miguel Alemán (1949) y otros proyectos públicos}

En 1949 la Dirección de Pensiones Civiles y de Retiro encargó al arquitecto Mario Pani Darqui un proyecto nunca antes realizado en Latinoamérica. Se trataba de una unidad habitacional de 1080 departamentos para 5000 personas. ${ }^{9}$ Siguiendo el modelo que entonces estaba desarrollando Le Corbusier en Marsella, Pani construyó lo que después se conocería como un multifamiliar, que además de las viviendas tenía espacios comunes, locales de renta, guardería, instalaciones deportivas y grandes espacios verdes.

Por otro lado consciente de la importancia no sólo estética sino social que las artes plásticas tenían en aquel momento, Pani invitó a los artistas José Clemente Orozco y Carlos Mérida a realizar murales dentro del conjunto. Con esa preocupación social y pensando en que éste fuera un proyecto integral, el arquitecto llamó a Clara Porset para realizar una propuesta de diseño de mobiliario y ambientes para los departamentos. La diseñadora se abocó con entusiasmo: “al diseñar los muebles mantuve siempre el propósito de que pudieran construirse con un costo muy bajo, y busqué el hacerlos tan resistentes, cómodos y agradables a la vista, como fuese compatible con la necesidad e intención de darles un costo reducido de fabricación" ${ }^{10}$. En ese mismo artículo Porset afirma que para 1950, la Dirección de pensiones había amueblado 108 departamentos. Sin embargo, un par de años más tarde, en 1953, en un artículo para la revista Espacios, ${ }^{11}$ Porset confiesa su decepción ante el proyecto fallido: “...se frustró por las mismas 
razones que otros esfuerzos semejantes han fracasado fuera de México. No se pudo imponer por la fuerza al inquilino la adquisición de los muebles que se habían creado adecuadamente para su vivienda, ni se pensó en convencerlo, buena y razonablemente, instruyéndolo sobre los nuevos enfoques del diseño en general y dándoles cultura de vivienda, en una palabra". ${ }^{12}$ Porset estaba convencida de que al pueblo mexicano le faltaba educación no sólo académica sino también en lo que al diseño y la cultura de vivienda se refería. Debido a esto, más tarde dedicó parte de su vida a enseñar y difundir una cultura del diseño.

Con Mario Pani además del Centro Urbano Presidente Alemán realizó diversos proyectos entre los que se encontraban la casa del mismo arquitecto en Acapulco (1952-53), y la casa Lima (1951) en Cuernavaca en la que, siguiendo el concepto de integración plástica, participó también el pintor Carlos Mérida.

Preocupada y ocupada, en hacer evidente el carácter social del diseño, Porset participó en varios otros proyectos públicos como fueron los hospitales de la Raza (1952) y la unidad de Nutrición del Centro Médico (1961) en colaboración con el arquitecto Enrique Yánez. Con Luis Barragán la unían principios en común: ambos buscaban darle un carácter mexicano a sus diseños pero integrándolos al contexto internacional. Porset no sólo realizó mobiliario para la casa-estudio del arquitecto ubicada en Tacubaya (1947), también desarrolló muebles para varias de sus casas entre ellas la Ortega (1940) y la Gálvez (1955-56), además de que realizaron una interesante colaboración para el hotel Pierre Marqués (1957) en donde Barragán realizó los jardines y Porset el mobiliario exterior.

Juan Sordo Madaleno fue otro de los destacados arquitectos de la época, con él Porset realizó proyectos comerciales como fueron: el Cine París (1954), el mobiliario exterior para el hotel Presidente de Acapulco en conjunto con Félix Candela (1958) y los muebles para la remodelación del Country Club Churubusco (1962).

\section{El arte en la vida diaria, objetos de buen diseño hechos en México, 1952}

En 1952 con el apoyo del Instituto Nacional de Bellas Artes, Clara Porset organizó El arte en la vida diaria. Exposición de objetos de buen diseño hechos en México. La primera exposición formal de diseño en un recinto museístico en México. Su intención era mostrar lo mejor del diseño artesanal nacional en diálogo con el diseño industrial.

Porset se enfrascó en una investigación que le implicó viajes y visitas lo mismo a fábricas que a talleres artesanales. En una carta que escribió Clara Porset a la crítica de Arquitectura Esther McCoy fechada el Lunes, 11 de Junio de 1951, mientras preparaba la muestra, la diseñadora relata:

La exhibición va maravillosamente bien. Creciendo tanto que estoy empezando a perder el aliento. Están auspiciándola las principales escuelas de Arquitectura y espero que las conversaciones que estoy teniendo con ciertos productores sobre las finanzas que se necesitan lleguen pronto a un punto concreto. Se están planeando dos concursos en conexión con la muestra: Uno con Celanese de México, para textiles y otro de Fibracel, un buen sustituto del masonite y de esta manera introducir el material a la rama de los muebles. Probablemente otro de Cerámica y vajillas de una fábrica en Guadalajara. ${ }^{13}$ 
41 La intención de la diseñadora era conjuntar en un mismo espacio los productos artesanales realizados en México y aquellos realizados en serie. ${ }^{14}$ Lograr un vínculo entre la industria, los artesanos y los artistas con el fin de tener mejor diseño y lograr implementar la producción industrial, así lo afirma en el catálogo el Arquitecto Enrique Yáñez, entonces director del Departamento de Arquitectura del Instituto Nacional de Bellas Artes: “...la limitación fundamental de la Exposición: costo asequible de las cosas, posibilidad ilimitada de reproducirlas y por tanto sentido social”. ${ }^{15}$

La muestra se presentó primero en el Palacio de Bellas Artes y después en los pasillos y espacios del recién inaugurado campus de la Universidad Autónoma de México.

Coincidió con el VII Congreso Panamericano de Arquitectura al que asistieron arquitectos de la talla de: Walter Gropius, Hannes Meyer, Marcel Breuer, Mies Van der Rohe, Herbert Bayer y Frank Lloyd Wright.

Porset logró mostrar diversos productos de naturalezas muy distintas que convivían armoniosamente. Además de sus propios diseños presentó trabajo en plata de William Spratling, los Hermanos Castillo y de la Platería Ortega; vidrio soplado de los Hermanos Ávalos, textiles de Riggs \& Sargent y de Elena Gordon; barro de Jalisco y de Michoacán, un sillón de bambú basado en los equipales tradicionales diseñado por Antonio Stevenson Méndez, una cortina de cobre para chimenea diseñada por el artista Germán Cueto, muebles de Domus, firma propiedad del arquitecto Michael van Beuren; muebles tradicionales, vajillas de la marca Loza Fina de Guadalajara, diseñadas por Eva Zeisel y, recipientes en cerámica fabricados por el taller Cerámica artística de Texcoco diseños de José Feher. En cuanto a los objetos producidos industrialmente, reunió utensilios de cocina La vasconia, las entonces novedosas cocinas integrales de DM Nacional, estufas de Acros, ollas de presión de Ekco y H Steel y lámparas de Mazi Lux, entre muchos otros objetos.

Desde finales del siglo XIX, la producción artesanal mexicana había sido de gran interés para muchos extranjeros quienes encontraban en las artesanías nacionales, objetos curiosos con impecable mano de obra. Sin embargo, con el discurso posrevolucionario que incluía una fuerte retórica indigenista, el arte popular se convirtió en un poderoso elemento nacionalista y parte fundamental de la construcción identitaria del momento: "Era imposible evitar ya en los años veinte, el peso simbólico de lo que se asociaba con la palabra folk o con el concepto de "popular" en un mundo cada vez más estandarizado e industrializado"16. Clara Porset entendió y adoptó este discurso nacionalista, así como la añeja preocupación de que con la llegada del progreso, poco a poco, iría muriendo la artesanía. Con una aguda visión, Porset decidió organizar esta exposición buscando ofrecer otra opción y lograr así evitar la crisis. Es pertinente reparar en la pequeña nota que Alfonso Caso escribió para el catálogo de la muestra y en la que denota tener la misma percepción que Porset:

No. El camino no está en mecanizar las artes populares, el camino está, como lo sugiere esta exposición, en hacer que los industriales que producen los objetos que consumimos todos utilicen a los artistas, que son capaces de concebir no sólo el objeto útil, sino el objeto bello; no sólo el objeto funcionalmente perfecto, sino aquél en que la intuición haya puesto ese otro elemento, tan indispensable para el hombre moderno, como fue indispensable para el hombre antiguo: la personalidad, el gusto por la forma noble, por el color agradable, por la decoración adecuada. ${ }^{17}$

El arte en la vida diaria. Objetos de buen diseño hechos en México, no sólo fue novedosa en el país porque contraponía -y al mismo tiempo buscaba complementar- artesanía, arte e 
industria, sino que innovó también en cuestiones museográficas. Hasta entonces no se habían presentado exposiciones que incluyeran objetos de diseño y aquellas que mostraban arte popular o artesanía referían a un montaje similar al de las tiendas de artesanías donde se mostraba todo mezclado sin ningún orden delimitado.

El arte en la vida diaria, marcó un nuevo camino. Porset -que había recorrido el mundo y sabía de las nuevas tendencias en cuanto a montajes museográficos- presentó las piezas, fueran únicas o producidas en serie, en vitrinas con la intención de destacar sus cualidades estéticas. Los textiles, se colocaron en mamparas y bastidores para que el público pudiera apreciar sus tejidos y texturas. Se buscó contextualizar muchas de las piezas mostradas creando ambientaciones. Complementó los objetos presentados con imágenes, que referían a retratos de artesanos trabajando o imágenes en gran formato de las obras arquitectónicas de entonces en la ciudad de México como era el multifamiliar Miguel Alemán (1949) de Mario Pani o el nuevo edificio en Avenida Reforma que ocupaba la Secretaría de Recursos Hidráulicos construido por el mismo Pani y Enrique del Moral (1950-52).

La diseñadora invitó también a la fotógrafa Lola Álvarez Bravo -con quien le unía una amistad y con la que ya había trabajado anteriormente- a realizar una serie de fotomontajes -en los que se mostraba la evolución de la industria mexicana y que fueron realizados por Fotomurales Escamilla.

Preocupada siempre por encontrar y destacar el carácter social del diseño Clara Porset logró en el Arte en la vida diaria, lo que no se había conseguido anteriormente en materia de exposiciones: presentar lo mejor de la industria, de la artesanía y del arte con el fin de que, unidos se complementaran creando un atractivo panorama que derivara en una mejor calidad de vida para la gente común. Esta exposición representó una metáfora de cómo valorar el pasado -la tradición-, poner en contexto el presente iniciando así la búsqueda de un mejor futuro, lo que iba a dar como resultado una verdadera, e infalible modernidad mexicana.

\section{La vuelta a Cuba}

Luego del triunfo de la Revolución cubana en 1959, Porset es invitada a regresar a su país natal para colaborar en el nuevo proyecto nacional. Fidel Castro consciente de que debía generar mejores condiciones de vida, encarga a la diseñadora varios proyectos:

El diseño y construcción del mobiliario para la ciudad escolar Camilo Cienfuegos, para 5,000 alumnos (1960); el diseño del mobiliario para la Escuela Nacional de Arte, la Escuela de Danza Moderna y la Escuela de Artes Plásticas de La Habana, construidas por el arquitecto Ricardo Porro (1961), y los muebles para la rectoría de la Universidad de la Habana (1962). También se le comisionó la creación de la primera escuela de Diseño en Cuba, impulsada directamente por Ernesto Che Guevara (1962), para generar el programa, visitó diversas instituciones de diseño en Estocolmo, Moscú, Varsovia, Praga, La Haya y Berlín. Una vez inaugurada la escuela (actualmente ISDI, Instituto Superior de Diseño Industrial); Porset es nombrada la primera directora, sin embargo las pugnas internas la hacen renunciar y alejarse definitivamente de la isla, desilusionada de los efectos de la Revolución.

Al regresar a México en 1963, decide compaginar el diseño con la docencia, integrándose al plantel de maestros de Facultad de Arquitectura en la UNAM donde se 
convierte en fundadora del curso de posgrado en Diseño Industrial al lado del arquitecto Horacio Durán.

En 1974 sobrevino la muerte a Xavier Guerrero y la diseñadora dejó de lado el diseño para dedicarse de lleno a la enseñanza hasta su muerte en 1981.

Su archivo y biblioteca se convirtieron en patrimonio universitario y bajo los auspicios de la Facultad de Arquitectura de la UNAM se vio cristalizada su última voluntad: la creación del Premio Beca Nacional de Diseño Industrial Clara Porset, con apoyo del Banco Nacional de Comercio Exterior y el Fideicomiso Clara Porset, que buscaba impulsar a mujeres diseñadores para siguieran sus estudios en el extranjero. A la fecha este proyecto sigue existiendo ya no como beca sino como un concurso que busca mostrar y alentar el trabajo de jóvenes diseñadoras procedentes de diferentes universidades en México.

\section{Conclusiones}

Clara Porset fue un personaje clave en la historia del diseño en México, no sólo por su práctica destacada y sus aportaciones al diseño y a la enseñanza de la disciplina sino porque fue una mujer que destacó en un mundo de hombres y supo entender las condiciones para realizar interesantes colaboraciones con destacados arquitectos.

A lo largo de las décadas de 1940 y 1950, el trabajo de Clara Porset tuvo una amplia difusión tanto en México como en el extranjero y fue premiado internacionalmente. Su habilidad para crear objetos funcionales que al tiempo de tener una sólida propuesta estética, reunieran los atributos para considerarlos con una cierta identidad nacional, la llevaron a ser un personaje reconocido en el ámbito internacional del diseño. Su trabajo no sólo puso su nombre en alto, sino que sirvió también para que diversos colegas y especialistas pusieran sus ojos en México y descubrieran que, entre muchas otras cosas, el diseño era también terreno fértil.

\section{BIBLIOGRAFÍA}

ABEDROP, Mónica y Lucy SPRINGAL del VILLAR. (1994) “El Neobarroco en la ciudad de México.

Ciudad de México: Museo de San Carlos/INBA.

COMISARENICO, Dina. (2006) Diseño Industrial. Mexicano e Internacional, memoria y futuro. Ciudad de México: Trillas.

De GARAY, Graciela. (2004)Mario Pani. Vida y Obra. Ciudad de México: UNAM/Facultad de Arquitectura.

DANLY, Susan. (2002) The Morrow Collection of Mexican Popular Arts. Alburquerque: edit. Casa Mañana y University of New Mexico Press.

GAMBOA, Fernando et al. (1985) El mueble mexicano. Ciudad de México: Fomento Cultural Banamex. 
HARRIS Mary Emma. (2002)The Arts at Black Mountain College. Cambridge, Massachussets: The MIT

Press.

SALINAS FLORES, Oscar. (2003) Historia del Diseño Industrial. México: Editorial Trillas.

SALINAS FLORES, Oscar. (2001) Clara Porset. Una vida inquieta, una obra sin igual. México: UNAM.

\section{Catálogos de exposiciones}

20 Centuries of Mexican Art/Veinte siglos de arte mexicano. México: MoMA/INAH, 1940.

El arte en la vida diaria. Exposición de objetos de buen diseño hechos en México. México: Departamento de Arquitectura del Instituto Nacional de Bellas Artes, 1952.

El objeto cotidiano en México. Ciudad de México: Instituto Nacional de Bellas Artes, 1969.

Diseño en México. Prospectiva y restrospectiva. Ciudad de México: Instituto Nacional de Bellas Artes, 1975.

\section{Hemerografía}

Arquitectura. Selección de arquitectura, urbanismo y decoración dirigida por el Arquitecto Mario Pani, se publicaba cuatro veces al año y su primer número vio la luz en diciembre de 1938 (la revista continúo hasta 1979).

Espacios. Revista integral de arquitectura y artes plásticas. Nació en septiembre de 1948, dirigida por los arquitectos Guillermo Rosell y Lorenzo Carrasco.

ROCHER, Mary. Furniture Depicts Different Mexico en New York Times. Nueva York: 4 de febrero 1947.

\section{Archivos}

Archivo Clara Porset Centro de Diseño Industrial (CIDI) /Universidad Autónoma de México, (UNAM), ciudad de México.

Esther McCoy Papers, 1896 -1989. En Archives of American Art Smithsonian Institute, Washington, DC.

\section{Semblanza de la autora}

Ana Elena Mallet (México, D.F. 1971) es curadora independiente y gestora cultural. Estudió la Licenciatura Literatura Latinoamericana en la Universidad Iberoamericana. Actualmente cursa una Maestría en Historia del Arte con especialidad en Estudios de Curatoriales en la UNAM.

Trabajó como curadora en el Museo Soumaya, en el Museo de Arte Carrillo Gil y fue subdirectora de programación del Museo Rufino Tamayo.

Fue curadora en jefe del Museo del Objeto el Objeto desde su Fundación en octubre de 2010 hasta Noviembre de 2011, institución donde aún permanece como asesora.

Como curadora independiente ha realizado diversas exposiciones de arte, moda y diseño en museos de México y el extranjero. 
De 2007 a 2012 coordinó para el Patronato de arte contemporáneo AC (PAC) la investigación, programación y realización del proyecto www.mexartdb.com, una página de consulta que busca poner a la mano la historia del arte contemporáneo en México de los últimos 20 años.

Ha sido docente en instituciones como la Universidad Iberoamericana, Centro y el Centro de la Imagen.

Entre 2010 y 2012 llevó la dirección curatorial del proyecto Destination: Mexico que llevó el trabajo de 60 diseñadores mexicanos a las tiendas de Museo de Arte Moderno de Nueva York en la propia ciudad de Nueva York y en Tokio.

En diciembre de 2011 en el marco del seminario organizado por la Fundación Cisneros y Bard Graduate Center for Decorative Arts: The Cisneros Seminar in the Material Cultures of the Iberoamerican World: Women Designers of the 20th Century, Shaping National Artistic Identities in Latin America; presentó una ponencia sobre Clara Porset

Desde 2006 es colaboradora de la sección de Artes de la Revista Harpers Bazaar en español, Gente y además colabora de diversas publicaciones culturales como Gatopardo, Chilango, DF por Travesías, Open, 1, Luna Córnea, Art Nexus, Código 06140 y La Tempestad entre otras.

Fue parte de los consejos consultivos de las siguientes instituciones: MUCA Roma/UNAM; Casa del Lago/UNAM y Casa Vecina (Fundación del Centro histórico). Así como miembro del comité de adquisiciones del MUAC/UNAM. También asesora de arte contemporáneo para el Centro Cultural Universitario de la Universidad de Guadalajara.

Durante 2011 y 2012 fue consejera de la sección de Cultura del periódico Reforma.

Actualmente trabaja en dos exposiciones de diseño latinoamericano para el Museum of Arts and Design (MAD) en Nueva York y el Americas Society también en Nueva York.

\section{NOTAS}

1. Clara Porset. "La decoración interior contemporánea. Su adaptación al trópico" (La Habana:Talleres tipográficos de Úcar, García y Co, 1931), p. 4.

2. Michael van Beuren llegó a México procedente de la Bauhaus en 1937, y unos años más tarde comenzó con su taller de diseño y producción de mobiliario que llevaba por nombre Domus. En 1942 su hermano Fredderick (Freddy) procedente de Nueva York llega a México y juntos convierten la fabrica en Muebles Van Beuren SA de CV. Esta fábrica fue la primera en diseñar y producir en serie, muebles asociados con los estilos modernos de la época y a precios accesibles para una nueva clase media mexicana. En su mejor momento, la fábrica llegó a producir más de 1000 sillas a las semana. Estuvo en manos de los hermanos Van Beuren hasta 1971 que la vendieron a la empresa alemana afincada en México, Singer. Freddy se casa con una aguerrida mujer artista y escritora Judith Martínez Ortega, y muere en 1992. Michael van Beuren murió en 2004 en Cuernavaca, Morelos.

3. Papeles de Walter Gropius no. 7/10, Bauhaus-Archiv Berlín. Citado en Anja Baumhoff, The Gendered World of the Bauhaus. The Politics of Power at the Weimar Republic's Premier Art Institute, 1919-1932, Peter Lang Frankfurt and New York: 2001, p. 53. Citado a su vez por Anja Baumhoff en "Female Careers at the Bauhaus" en Bauhaus, Art as Life (Londres, Barbican Art Gallery/Koening Books, 2012), p. 238.

4. Mary Rocher, "Furniture Depicts Different Mexico" en New York Times. (Nueva York: 4 de febrero 1947), p. 49.

5. Ibidem 
6. En entrevista personal con un destacado alumno de Clara Porset el arquitecto Alberto Hentschel en abril de 2004, describió el carácter de Porset y cómo en 1959 cunado decide partir a Cuba para apoyar la Revolución tiene una fuerte discusión con el arquitecto Luis Barragán quién le dice que si ella se decide por Cuba, él jamás la volverá a contratar. Porset lo confronta y le dice que ante todo están sus creencias y principios. Así, aún cuando la diseñadora regresó a vivir a México, no volvió a colaborar con Barragán, prueba de su determinación y fuerte carácter.

7. En octubre de 1933, la Sociedad de Arquitectos Mexicanos (SAM) organizó en la biblioteca de en la Escuela de San Carlos, una serie de pláticas sobre la arquitectura moderna, sus caminos y sobre el oficio y la labor del arquitecto. Esta discusión fue nodal para el devenir de la arquitectura moderna en México y para insistir que por sobre todo la arquitectura debería resolver necesidades de los usuarios, es decir ser funcional antes que bella. Entre los asistentes estaban: Juan Legarreta, Salvador Roncal, Álvaro Aburto, Manuel Ortíz Monasterio, Mauricio M. Campos, Federico Mariscal, Juan Galindo, José Villagrán García, Silvano B. Palafox, Manuel Amábilis, Juan O'Gorman, Antonio Muñoz, Ing. Raúl Castro Padilla, y Alfonso Pallares.

El temario buscaba resolver las siguientes preguntas:¿Qué es la arquitectura ?,¿Qué es el funcionalismo ?, ¿Puede considerarse el funcionalismo como una etapa definitiva de todo devenir arquitectónico ?, ¿Debe considerarse el arquitecto como un simple técnico de la construcción o como un impulsor, además, de la cultura general de un pueblo ?, ¿La belleza arquitectónica, resulta necesariamente de la solución funcional o exige , además, de la actuación consciente de la función creadora del arquitecto ?,¿Cuál debe ser la orientación arquitectónica actual en México ? Las discusiones fueron candentes por decir lo menos. Los arquitectos fijaron posturas y fue quizá en estos diálogos donde se determinó mucho del camino que seguiría la arquitectura moderna en el país. Tanto arquitectos maduros como jóvenes eufóricos marcaron sus posiciones: para el joven Álvaro Aburto la arquitectura mexicana debía ser "pobre y desnuda, como somos nosotros, como es el pueblo mexicano". Federico Mariscal, afirmaba que "la orientación de la arquitectura en México no debe obedecer a nada diferente respecto a la orientación de la arquitectura en cualquier otro punto de la tierra", mientras que Manuel Amábilis pugnaba porque toda arquitectura fuera funcional, pero funcional como un árbol que surge de la tierra y no como una máquina de ingeniero. Para O'Gorman la arquitectura se acercaba más a una ciencia que a un arte y por lo mismo debía concentrarse en otorgar soluciones y no distraerse en el ornamento que más bien remitía a lo burgués. Para ilustrar su ideas decide publicar El arte artístico y el arte útil.

Estas discusiones trajeron nuevos bríos para luchar contra los estilos preponderantes e de la época que hacían referencia a estilos pasados (el neocolonial).

De esta discusión se desprende la categorización que ciertos estudiosos han dado a los arquitectos funcionalistas mexicanos: los Integristas, dispuestos a integrar estilos de otros momentos históricos; los Radicales que buscaba despojar a la arquitectura de todo ornamento y entenderla como una herramienta para generar soluciones; y los Socialistas que buscaban llevar las premisas de lo funcional urbano al campo.

8. Cfr. Mónica Abedrop y Lucy Springal del Villar. "Arquitectura de la ciudad de México de los años 20 a los 50" en El Neobarroco en la ciudad de México. (Ciudad de México: Museo de San Carlos/ INBA, 1994)

9. Ver Graciela de Garay. Mario Pani, Vida y obra. (Ciudad de México: UNAM/Facultad de Arquitectura, 2004), p. 37.

10. Clara Porset. "El centro urbano "presidente Alemán" y el espacio interior para vivir". En Arquitectura. Selección de arquitectura, urbanismo y decoración. No. 32 (ciudad de México, Octubre, 1950)

11. Espacios. Revista integral de arquitectura y artes plásticas nació en septiembre de 1948 y estaba dirigida por los arquitectos Guillermo Rosell y Lorenzo Carrasco. Cerró en 1957 y se editaron 40 números y una guía especial de arquitectura. Su diseño gráfico era de lo más elegante y original en formato horizontal y terminó por convertirse en un objeto artístico coleccionable. Espacios fue, 
de alguna manera, la respuesta a la revista Arquitectura. Selección de arquitectura, urbanismo y decoración dirigida por el arquitecto Mario Pani que se publicaba cuatro veces al año. Su primer número vio la luz en diciembre de 1938 (la revista continúo hasta 1979). Ambas publicaciones buscaron ademñas de difundir la arquitectura moderna nacional, contextualizarla $-\mathrm{y}$ hasta compararla- con lo que sucedía en otras partes del mundo.

12. Clara Porset. "Diseño viviente. Hacia una expresión propia en el mueble" en Espacios revista integral de arquitectura y artes plásticas. Número 16, (Ciudad de México, julio 1953).

13. Archivo Esther McCoy Smithsonian Institute, Washington. Carta de Clara Porset a Esther McCoy fechada el Lunes 11 de junio de 1951. El material original se encuentra en inglés. La traducción es mía.

14. Durante aquellos años del renacimiento mexicano hubo un grupo de mujeres artistas e intelectuales cuya obra y vida personal se vieron fuertemente influenciadas por el arte popular que de alguna manera, era reflejo de identidad. Desde Tina Modotti y sus imágenes de vasijas y objetos tradicionales y Rosa Rolanda con sus fotografías de personajes rodeados de artesanías, pasando por pintoras como Olga Acosta, Frida Kahlo, María Izquierdo que se destacaron por naturalezas muertas con objetos populares hasta escritoras y promotoras como Judith Martínez Ortega, Frances Toor o Anita Brenner que se convirtieron también en activas coleccionistas de objetos populares.

15. Enrique Yáñez. "La Exposición, El arte en la vida diaria" en El arte en la vida diaria. Exposición de objetos de buen diseño hechos en México. (Ciudad de México: Departamento de Arquitectura del Instituto Nacional de Bellas Artes, 1952), p. 11.

16. James Oles. "Seducción o negocio. Las exposiciones de arte popular mexicano 1820-1930" en Casa Mañana The Morrow Collection of Popular Arts. Edited by Susan Danly (Alburquerque: University of New Mexico Press, 2002), p. 31.

17. Alfonso Caso. Nota en el catálogo de la muestra El arte en la vida diaria. Exposición de objetos de buen diseño hechos en México. (Ciudad de México: Departamento de Arquitectura del Instituto Nacional de Bellas Artes, 1952), p. 10.

\section{RESÚMENES}

Este texto busca presentar algunos aspectos de la vida y obra de la diseñadora cubana radicada en México, Clara Porset, quien es uno de los personajes más destacados de la historia del diseño en México.

Se narra desde su adolescencia en Cuba en busca de una vocación, su paso por instituciones destacadas en el diseño mundial como Black Mountain College donde estudió bajo la tutela de Josef Albers, hasta su llegada a México donde, impulsada por su marido el pintor Xavier Guerrero se adentra en la cultura mexicana encontrando en ella fuente de inspiración y de trabajo.

El mobiliario tradicional mexicano y las artes populares fueron referencias fundamentales en el trabajo de esta diseñadora que tomó el Butaque como emblema de diseño y trabajó alrededor de él generando un referente cultural directamente asociado con la identidad local.

This text presents some aspects of the life and work of Clara Porset a Cuban designer living in Mexico, one of the most outstanding characters in the history of industrial design in Mexico. The narration spins off from her adolescence in Cuba, looking for a vocation, her passage through different institutions well known in the global design scene like Black Mountain College where 
she studied under Joseph Albers, until her arrival in Mexico where she was encouraged by her husband, painter Xavier Guerrero, to delve into Mexican culture finding in it a source and inspiration for her work.

Traditional Mexican furnishing and popular arts were fundamental references in the work of the designer who worked incorporating them and became a cultural reference associated with local identity.

ÍNDICE

Keywords: industrial design, Mexico, furniture

Palabras claves: diseño industrial, México, muebles

\section{AUTOR}

\section{ANA ELENA MALLET}

Estudiante de posgrado en Historia del Arte, Facultad de Filosofía y letras, Universidad Autónoma de México

Correo electrónico: aemallet[at]gmail.com 